\title{
Learning Strategies in L2 Settings in Saudi Arabia: An Annotated Bibliography
}

Fahad Alqurashi*

Department of English, Umm Al-Qura University, Makkah, Saudi Arabia

Corresponding Author: Fahad Alqurashi, E-mail: fmqurashi@uqu.edu.sa

\section{ARTICLE INFO}

Article history

Received: July 09, 2018

Accepted: August 22, 2018

Published: December 01, 2018

Volume: 7 Issue: 7

Advance access: October 2018

Special Issue on Language \&

Literature

Conflicts of interest: None

Funding: None

\begin{abstract}
Teaching English as a second/foreign language has gained increasing significance all over the world. Investigating learning strategies has become one of the major areas of research in the expanding field of L2 acquisition. Many researchers have addressed various aspects and different issues related to this field. This annotated bibliography is designed to be of help to researchers working on learning strategies in second/foreign language settings and to provide language teachers with a solid theoretical and pedagogical background based on data of many types from different angles to enhance their teaching. The current work is by no means exhaustive, but an attempt to give an overview of the field and highlights published studies written on a variety of topics related to learning strategies in the context of teaching English as a foreign language in Saudi Arabia. Works listed in this annotated bibliography are divided into two categories; journal articles and dissertations and theses. Studies in each category are arranged alphabetically by author and for each work there is a brief non-evaluative synopsis of the study objectives, instrument(s) of data collection, and results.
\end{abstract}

Key words: Learning Strategies, Second/foreign Language, Annotated Bibliography

\section{JOURNAL ARTICLES}

1. Ahmed, O. N. (2012). The effect of different learning styles on developing writing skills of EFL Saudi learners. British Journal of Arts and Social Sciences, 5(2), 220-233. This study involved 50 first year female students at Yanbu University College studying Bachelors of Computer Science and Management Information Systems to test the effectiveness of using different learning styles on developing their writing skills. Students were randomly divided into a control group, that received conventional teaching, and an experimental group that was exposed to a systematic training of some activities based on their learning styles and finished a learning style inventory. A writing test was used as a pre-post test and Grasha-Reichmann Student Learning Style Scale were used to determine students' learning styles. Results indicated that the writing skills of the experimental group improved far better than those of the control group.

2. Alhaisoni, E. (2012). Language Learning Strategy Use of Saudi EFL Students in an Intensive English Learning Context. Asian Social Science, 8(13), 115-127.

This study investigated the effect of gender and proficiency level on the type and frequency of language learning strategies used by 701 EFL students in an intensive English language program at Hail University. Surveyed students used language learning strategies with low to medium frequency and preferred to use cognitive and metacognitive strategies the most and affective and memory strategies the least. No significant gender differences were reported in the use of language learning strategies except for social strategies, where females reported using LLS more significantly than males. The study found female students tend to use overall language learning strategies more often than males and that highly proficient students tended to use all six categories more than low-proficiency students.

3. Alhaysony, M. (2012). Vocabulary discovery strategy used by Saudi EFL students in an intensive English language learning context. International Journal of Linguistics, 4(2), 518- 535.

The author surveyed a sample of 746 male and female Saudi EFL students to explore their preferred vocabulary discovery strategies (VDS). The participants were enrolled in an intensive English language programme at the University of Hail and responded to a questionnaire. The study found students used different VDSs. The most frequently used strategy categories were social and skipping strategies while guessing and dictionary strategies were used less frequently. Female participants were more active in using all the strategies more frequently than males with a statistically significant difference in guessing and skipping strategy. Moreover, females used social and dictionary strategies more than males according to mean differences, but without statistically significant difference.

4. Al-Hebaishi, S. M. (2012). Investigating the relationships between learning styles, strategies and the academic performance of Saudi English majors. International Interdisciplinary Journal of Education, 1(8), 510-520. 
This study utilized mixed methods to identify the learning style and strategies preferences and their relationship with academic performance. Data were collected from a sample of 88 female participants of EFL majors at Taibah University. The majority of participants preferred the visual learning style and employed cognitive strategies followed by metacognitive strategies. Significant relationships have been found between the visual learning style with both memory and affective strategies. No significant relationship between learning styles and academic performance have been found. Results were discussed without referring to the findings of similar studies.

5. Alkubaidi, M. A. (2014). The relationship between Saudi English major university students' writing performance and their learning style and strategy use. English Language Teaching, 7(4), 83-95.

The purpose of this study was to look at the link of learning style preferences with writing strategy use and various proficiency levels. Date were collected from 74 Saudi female undergraduate students in their final year of their bachelor degree in King Abdulaziz University who responded to two questionnaires: (a) the Perceptual Learning Style Preference and (b) a writing strategy questionnaire in addition to a writing task. The study found no correlation between the participants' learning style preference and writing strategies, nor their use of writing strategies and their writing proficiency. Most participants were auditory and group learners and used more prewriting strategies than during writing strategies and reviewing strategies.

6. Al Maghraby, M. A. \& Alshami, A. M. (2013). Learning style and teaching method preferences of Saudi students of physical therapy. J Family Community Med, 20(3), 192-197.

Determining the learning styles and preferred teaching methods of Saudi physical therapy students was the focus of this paper that utilized a cross-sectional study design. The study sample included 53 students of physical therapy (21 males and 32 females) who responded to two questionnaires on preferred learning styles and teaching methods. Most students (59\%) preferred the concrete-sequential learning style among mixed styles on the other style dimensions: Abstract-sequential, abstract-random, and concrete-random. The study concluded with recommending that educators consider diverse learning styles of the students and also utilize a variety of teaching methods in order to promote an optimal learning environment for the students.

7. Almigbal, T. H. (2015). Relationship between the learning style preferences of medical students and academic achievement. Saudi Medical Journal, 36(3), 349-355.

This study surveyed 600 medical students at King Saud University using descriptive and analytical statistics were to explore the learning style preferences and their relationship to academic achievement, gender, marital status, residency, different teaching curricula, and study resources. Findings showed that 261 students (43\%) preferred to learn using all VARK modalities while learning style preferences were not related to their academic achievements, marital status, residency, or study resources. Learning style preferences were found significantly related to the learners' favored teaching curricula. The study used a cross-sectional method that involved participants studying medicine in their second, third, fourth, and fifth year which is not the ideal study design for determining relationships between variables.

8. Al Nooh, A. (2013). The Effectiveness of Reading Techniques Used in a Saudi Arabian Secondary School Classroom as Perceived by Students and Teachers: A Study of Methods Used in Teaching English and their Effectiveness. Arab World English Journal, 4(3), 331- 345

This paper explores the perceptions of 4 female high school teachers and 30 female grade 10 students (age 16-18) regarding the effectiveness of currently employed pedagogical strategies of teaching English reading skills. The study implemented mixed methods: quantitative, questionnaires, qualitative, interviews and focus-group discussions. Findings indicated that teachers used different resources in teaching English reading such as worksheets and supplementary materials from the Internet and newspapers. Students complained about the opacity of lesson objectives and the desultory approach of the teachers which resulted in their getting lost in the discussion. The author did not elaborate on how the used teaching materials affected students' reading skills and competence.

9. Alqarni, I. R. (2018). Saudi English Major Freshmen Students' Vocabulary Learning Strategies: An Exploratory Study. International Journal of Applied Linguistics \& English Literature, 7(1), 141-145.

The author of this study explored the vocabulary learning strategies (VLSs) employed by Saudi Freshmen students majoring in English as a foreign language (EFL). The sample of the study included 81 Saudi male students in their first semester in the English Department at King Saud University. The questionnaire results showed that the participants used all of the different vocabulary learning strategies with different degrees of frequency. Metacognitive strategies were the most used and/or preferred strategies by all participants, followed by social strategies, determination strategies, cognitive strategies and memory strategies respectively. However, the overall mean score of (1.63) for the use of the strategies indicated that the participants of this study were low/poor users of vocabulary learning strategies in general.

10. Al-Refay, N. \& Koura, A. (2010). Language Learning Strategies Used by Saudi secondary School Students and their Relationship to Achievement in ESL. $30^{\text {th }}$ CDELT National Symposium on English Language Teaching. $26^{\text {th }}-27^{\text {th }}$ October. AinShams University. Cairo

This study examined the language learning strategies used by high school students in relation to their academic achievement. A modified version of Oxford' Strategy Inventory Language Learning has been used to collect data from 160 high school students in Yanbu. The study found that the surveyed students preferred to use LLSs in the following order: cognitive, metacognitive, memory, social, affective, and finally compensation strategies. The frequency of using LLSs by female and high achieving students was significantly greater than that of male and low achieving students. In addition, the most frequently used LLSs by high achieving 
students, both male and female, were metacognitive and social strategies followed by compensation strategies.

11. Al-Saud, L. M. 2013 Learning Style Preferences of First-Year Dental Students at King Saud University in Riyadh, Saudi Arabia: Influence of Gender and GPA. Journal of Dental Education, 77(10), 1371-1378

The researcher surveyed in this study 113 first-year dental students (42 female, 71 male) at King Saud University to investigate the effect of gender and past academic performance on learning style preferences. The Visual, Aural, Read-write, and Kinesthetic (VARK) questionnaire was used and results showed that $95 \%$ of the students favored multimodal learning preferences. Gender differences were not statistically significant. A statistically significant difference was found in the mean values of GPA where students with a lower mean GPA showed single learning style preference than those with multiple (quad-modal) learning style preferences. However, results related to students' GPA might not be reliable because GPAs were self-reported by the students themselves and not officially checked.

12. Al-Seghayer, K. (2014). The impact of gender and reading proficiency level on online reading strategies employed by EFL learners. Journal of Educational Sciences of King Saud University, 6 (2), 493-509.

This study reports on an experiment that tested the utilization of metacognitive online reading strategies of 100 male and female Saudi undergraduate EFL learners majoring in English. The results showed that the most frequently strategy used was support, followed by problem-solving, while global strategy was the least used. No significant differences were found between proficient and less-proficient EFL learners in terms of using the three categories of online reading strategies. Female learners' use of the online global reading strategy was significantly higher than that for males. No other statistically significant differences with reference to gender were found.

13. Al Tale', M. A. (2016). Utilizing Learning Styles in EFL Teaching. International Journal of Language and Linguistics, 3(6), 81- 86.

This article investigated the different learning styles of 108 Saudi EFL female students at varying levels within the English department at King Khalid University. Data were collected through a learning style test as well as classroom observation and interviews. The study found that most students employed mixtures of the three main learning styles (visual, auditory, and kinesthetic). The interviews indicated that most of the participants were not aware of their learning styles. After being made aware of them, many learners do not think that their teachers use teaching styles suitable for their learning styles. Classroom observation revealed that students displayed different types of classroom behaviour that the researcher attributed to the different preferred learning styles.

14. ArifA. M. H. Al-Ahdal \& A. A. H. Al-Ma'amari. (2015).

Learning Strategies of the Arab EFL Learners: Finding

Correlation with Outcomes. Advances in Language and Literary Studies, 6(5), 230-241.

The present study examined the strategies of good and poor language learners for the sake of encouraging language teachers to highlight the successful strategies to ensure better learning outcomes. A questionnaire was administered to 160 Saudi high school students and findings indicated that cognitive and meta-cognitive strategies were the most successful for that sample. The paper concluded with highlighting the teachers' role in raising the students' awareness of different strategies and the importance of educating the teachers in the use of these strategies. Even though the authors stated that they utilized interviews with the teachers to collect data, the article did not mention anything about the interviews' findings.

15. Choudhary Z. J., Al-thubaiti, T. S., \& Uthman, A. (2013).

Effects of English language proficiency on the choice of language learning strategies by Saudi English-major undergraduates. English Language Teaching, 6(1), 35-47.

This study reported favourably on the effect of using language learning strategies more frequently to achieve high English language proficiency. The study sample included 240 English-major undergraduates at Taif University participated in the study and responded to the Strategy Inventory for Language Learning questionnaire. Metacognitive strategies were the highest used strategies followed by social and cognitive LLS respectively. Compensation and affective strategies showed mixed preferences but memory strategies were assigned the least mean values. A positive correlation has been found between the frequency of using language learning strategies and high English language proficiency which the authors took as an indication that the usage of language learning strategies should be taught explicitly to achieve better student outcomes.

16. McMullen, M. G. (2009). Using Language Learning Strategies to Improve the Writing Skills of Saudi EFL

Students: Will it Really Work? System, 37(3). 418-433.

The author investigated in this study the effect of gender and academic major on the use of language learning strategies by Saudi EFL students inside the Kingdom of Saudi Arabia. The study also explores if LLS usage could have any potential benefits for Saudi students in the area of strategy instruction. There were 165 participants (71 male and $94 \mathrm{fe-}$ male) from three sample universities, enrolled in similar Freshman English composition courses. All the participants responded to Oxford's Strategy Inventory for Language Learning (SILL). Results indicated that female students used slightly more LLSs than male students, and Computer Science students used slightly more LLSs than Management Systems students. The author highlighted the significance of direct strategy instruction being to motivate new avenues for approaching the teaching of Saudi students.

17. Nuzhat, A., Salem, R., Quadri, M., \& Al-Hamdan, N. (2011). Learning style preferences of medical students: a single-institute experience from Saudi Arabia. International Journal of Medical Education; Nottingham, 2. 70-73.

This study examined the preferred learning styles of undergraduate medical students at King Saud Bin Abdul Aziz University for Health Sciences. The study sample included 146 preclinical students (74 males and 72 females) who responded to the validated VARK questionnaire that consistsed of 16 items which identified four different learning styles: visual, aural, reading/writing and kinesthetic. The results showed that $72.6 \%$ of students preferred multimodal learn- 
ing styles while 5.5\%, preferred the visual, $11.6 \%$ preferred the aural, $2.1 \%$, preferred the reading/writing and $8.2 \%$ preferred the kinesthetic modes. The authors considered these findings an improvement in the quality of the teaching and learning experiences of students.

\section{DISSERTATIONS \& THESES}

1. Al-Abbasi, J. A. A. (2007). Beliefs and vocabulary learning strategies in Saudi Arabia. PhD dissertation, University of Nottingham.

The author surveyed 392 female Saudi EFL students in the western province of Saudi Arabia to assess their knowledge and use of vocabulary learning strategies. The study utilized qualitative and quantitative methods to provide an in-depth view of how their beliefs and use of vocabulary learning strategies were interrelated. Results showed that the participants were oriented towards implementing Arabic-based strategies more than English and some social strategies such as 'ask a classmate' or 'ask the teacher' more than group work-based strategies. The strategies the students employed the most while learning their vocabulary were repetition and guessing. Students' input confirmed that there was an interrelationship between some of the beliefs and the use of vocabulary learning strategies.

2. Al-Asmary A. A. (2007). The Effect of Learning Strategies on Vocabulary Learning by King Saud University Students Majoring in English. MA Thesis, King Saud University.

This study employed a questionnaire and a proficiency test to account for the vocabulary learning strategies used by 47 Saudi English majors at King Saud University. In addition, the author explored the relationship between strategy use and participants' overall achievement in learning vocabulary. The results revealed that students did not hold a strong tendency to use rote memorization of vocabulary items, but demonstrated clear preferences for context-based and usage-related vocabulary learning styles as well as oral and visual repetitions when responding to rehearsal strategies. Dictionary strategies for comprehension have been mostly utilized and more often used than extended dictionary and look-up strategies. Encoding-related strategies have not been used heavily except visual encoding while all activation strategies have been neglected although extensively reported in the literature. Selective attention, as a metacognitive strategy, has been more extensively used than self-initiation. In addition, four correlations were found to be statistically significant in the results of the 40-item test that measured the students' breadth of vocabulary. These four correlations were very weak and ranged from 0.29 to 0.35 . Namely, they were the correlation coefficients between visual repetition and visual encoding, and the degree of achievement and the correlation coefficient of self-initiation and the degree of achievement respectively.

3. Al-Braik, M. S. (1986). Investigation of the successful attributes of English as a second language of Saudi Arabian Students studying in the United States of America. $\mathrm{PhD}$ dissertation, Pennsylvania State University.

The researcher surveyed 176 graduate and undergraduate Saudi students studying in the United States to investigate language learning strategies along with cognitive factors, attitudes, motivation, and personality characteristics as fac- tors which contributed to the successful language learning attributes. The participants responded to a questionnaire consisting of 45 items. Findings revealed that all participants judged themselves as successful language learners and presented an overall agreement that these attribute subcategories were important variables in learning a foreign language. Attributes of cognitive factors were first rated by participants followed by an attitudinal and motivational factors followed by personality characteristics while attributes of learning strategies were rated last by participants. More particularly, students who started learning English between the ages of 7 and 12 showed better learning strategies than those who started at older ages.

4. Albousaif, M. A. (2012). Factors determining Saudi learners' difficulties in attaining EFL vocabulary. $\mathrm{PhD}$ thesis, University of Newcastle.

This research explored which strategies Saudi EFL learners used and the reasons for using or not using those strategies in each stage of vocabulary learning. The study had the following research questions: 1) How do Saudi learners learn EFL vocabulary? Are they using the most effective methods in their vocabulary learning? 2) How do Saudi L2 learners (and their teachers) understood the concept of "vocabulary knowledge'? 3) What are the vocabulary-learning strategies that are most preferred and most utilised by Saudi EFL learners? 4) What are the learners' reasons for using/not using those strategies? 5) Which learning strategies might be the most effective and the most motivating for students in ways that contributed to their overall SLA? 6) To what extent were Saudi EFL learners aware of the significance of autonomous vocabulary learning? Data were collected through a structured questionnaire, administered to 200 Saudi EFL students to investigate their learners' experiences, and semi-structured interviews that involved 20 of the participants to obtain deeper insights into their use and understanding of vocabulary-learning strategies. Questionnaire results revealed that upper-level students tend to make use of their dictionaries and used strategies of guessing, grouping words, and connecting words to personal experiences more than their lower-level counterparts who tended to make use of the strategies of encoding and verbal and written repetition. The interviews revealed that the majority of the students did not have enough support from their teachers in vocabulary-learning strategies to become independent learners and consequently, they had to depend on their teachers to learn new vocabulary.

5. Al-Fuhaid, M. (2004) Vocabulary learning strategies: an empirical study of their use and evaluation by Saudi EFL learners majoring in English. PhD thesis, Durham University.

This study investigated the use and evaluation of vocabulary learning strategies (VLSs) by Saudi EFL (as opposed to ESL) learners majoring in English in Qassim Imam University, Saudi Arabia. Three research methods were used to achieve the aims of the study. First, a questionnaire survey was used with questions about a set of VLSs based on a taxonomy devised by the experimenter. The study sample included 50 undergraduate students in their final year $\left(7^{\text {th }}\right.$ and $8^{\text {th }}$ levels) at the Department of English and Translation. 
Their responses to the questionnaire showed that Saudi English majors tended to use both the general and the more specific VLSs quite infrequently. In addition, their strategy use was generally not directed towards the type of strategies that required elaboration, active mental processing or dedication. The second method was a tape-recorded think-aloud-protocol experiment where the participants were asked to read five texts, verbalizing their comprehension of the texts and their way of dealing with unknown words. The analysis of the 47 subjects' TAPs revealed some striking findings. The TAPs of a considerable number of subjects made apparent a number of areas of weakness in terms of both use of word-solving strategies, and L2 vocabulary proficiency level. The third method was individual interviews with 10 students conducted afterwards in order to probe some aspects of the subjects' use and evaluation of VLSs in greater detail. Interview data revealed that Saudi EFL learners do not use social strategies frequently and rely on course, minimum independent study, restricted range of self-initiated activities, minimum record of lexical items, and do not read the dictionary example sentences because the sentence in which the new word appears is enough for them.

6. Alharthi, T. (2011). The Impact of Writing Strategies on the Written Product of EFL Saudi Male Students at King Abdul-Aziz University. PhD thesis, University of Newcastle.

The aim of this study was to investigate the composing processes and strategies in the written composition of final-year Saudi male students majoring in English at King Abdul-Aziz University in order to gain a deeper understanding of the sub-processes of writing, such as planning, structuring, reviewing, and revising and to understand some of the reasons behind their poor written output. It also aims to investigate the way skilled and less-skilled students composed their English writing, to classify the differences in the use of strategies between the two groups, and to study the impact of using strategies on the written product. The collected data included written samples, a writing strategy questionnaire (WSQ), and think-aloud protocols (TAP). The findings of the data analysis indicated first that the students had problems at the sentential and intersentential levels. Second, the findings show that the students were conscious of writing strategies, so they were expected to plan, translate and edit their writing. Third, the findings of the WSQ revealed that students do not report what they actually did. Fourth, the results of the analysis of the TAPs showed that the students used mainly meta-cognitive, cognitive, and affective strategies. However, only skilled students planned their writing globally or locally, and both skilled and less-skilled students were involved in the cognitive process.

7. Alhaysony, M. H. (2008). Saudi-female English major students' writing strategies in L1 (ARABIC) AND L2 (English). PhD thesis, University of Essex

Writing processes and strategies in L1 (Arabic) and the L2 (English) used by Saudi $3^{\text {rd }}$ year English female college students have been investigated in this study to discover cross-subject and cross-language features in two perspectives: (1) writing similarities between L1 and L2; (2) the writing strategies that better and poorer writers reported and used. Data were obtained via a questionnaire, think-aloud protocols, and semi-structured interviews. The researcher found that subjects used similar strategies in composing in Arabic and English and their writing process was recursive in nature as proved in previous studies. Good and poor writers used the same writing strategies, but good writers claimed, according to their questionnaire responses, to use writing strategies more frequently than poor writers in both languages maybe because they were more aware of writing strategies. In addition, poor writers used L1 to facilitate their writing in L2 more than good writers and tended to create plans either mentally or in written form in Arabic, questioning either for planning or for vocabulary, spelling. Some of them went further by writing the whole text or parts of it in Arabic first then translated it which indicated that L2 writing seemed to be a bilingual event for them.

8. Aljuaid, H. (2015). Language Learning Strategies Used by a Group of Saudi Arabian EFL Learners. PhD thesis, Griffith University.

This $\mathrm{PhD}$ thesis aimed at exploring the patterns of language learning strategy use as perceived and reported by a specific group of Saudi Arabian EFL learners. The study used a mixed method approach (semi-structured interviews and a questionnaire- The Strategy Inventory for Language Learning). The participants of the experiment were 400 students who were enrolled in an English Language and Literature BA program at Taif University, a state university in Saudi Arabia. Analysis of the quantitative data revealed that the six learning strategies were used by all of the students as follows: a) metacognitive strategies were the most highly used ones since they allow L2 learners to comprehend and process of their knowledge of the target language. b) Memory strategies were the least used ones because only low level L2 learners memorize verbs and grammar units without comprehending their meaning and value cognitively. c) Social, affective, cognitive, and compensation strategies were used to an intermediate extent with no significant differences found between them. Qualitative data, obtained through semi-structured interviews with 20 participants, indicated that culture and religious beliefs may be a motivation for students to learn a foreign language, specifically for religious purposes (to perform missionary work, for example). A good point in the analysis of qualitative data was the reference to a generational gap through which the younger participants showed more readiness to embrace English as a foreign language than older participants. Another critical finding in the data indicated that employability prospects were considered an important motivator as far as learning English is concerned, which reflects an advanced level awareness of the requirements of the labour market in Saudi Arabia.

9. Alkahtani, M. (2011). Learning styles of EFL Saudi college-level students in online and traditional educational environments. $\mathrm{PhD}$ dissertation, Indiana University of Pennsylvania.

The purpose of this study was to examine Saudi EFL college students' perceptual learning styles in order to determine whether their perception of their learning styles is a predictor of academic persistence, satisfaction and success in different learning environments. Participants' perceptions about their 
learning styles in both online-based and class-based environments, and their resulting satisfaction/dissatisfaction and persistence/nonpersistence decisions, were explored. This study employed a concurrent mixed-method approach. Quantitatively, 100 college level Saudi EFL students responded to the Perceptual Learning Styles Preference Questionnaire (PLSPQ) to elicit their learning styles. Qualitatively, individual in-depth interviews were conducted with two groups that were comprised of six students each representing the two modes of instruction students chose during this study to examine the students' learning styles to their choices, experiences, and satisfaction. The study findings revealed the following results: 1) The participants' preferred learning styles were as the following order: Tactile, auditory, visual, group, kinesthetic and individual. 2) The study found no clear correlation between the students' preferred styles and their choice of instructional mode while students' satisfaction and success, as well as their positive and negative learning experiences, correlated with their learning style preferences. 3) The study supported the idea that students' perceptions of their learning styles are affected by their personality types, cultural beliefs, and teacher's teaching style. 4) The study showed that Saudi EFL students preferred online classes for reasons other than those dictated by their learning styles. 5) The participants believed that learning styles affected their use of learning strategies as well as their motivation and confidence in different class formats.

10. Alkahtani, S. S. (2016). Language learning strategies among Saudi EFL college students and their relationship to students' perceptual learning style, gender, academic major and proficiency level. $\mathrm{PhD}$ dissertation, University of Tennessee.

This study reported on an experiment that involved 667 Saudi EFL college students, 440 males and 227 females, studying at Yanbu English Language Institute. The study investigated the type and the frequency of language learning strategies and perceptual learning style preferences of the participants, the relationship between the students' perceptual learning style preferences and their use of various types of language strategies, and the influence of genders, academic disciplines and language proficiency levels on the students' preferences to employ different language learning strategies. Data were collected via two self-reported questionnaires, Oxford's (1990) Strategy Inventory for Language Learning (SILL) and Reid's (1995) Perceptual Learning Style Preference Questionnaire (PLSPQ). Data analysis indicated that participants employed language strategies moderately in the following order: metacognitive, social, compensation, cognitive, memory and affective strategies. The overall dominant perceptual language style preferences were auditory and group. Significant correlations were found between perceptual language learning styles and the use of language learning strategies. The strongest correlations existed between visual, auditory, kinesthetic styles and metacognitive strategies. Females tended to employ strategies slightly more often than males, while technical and engineering participants used strategies slightly more often than those in nontechnical fields. Participants who were less proficient in English employed more affective strategies than did participants who had more advanced English proficiency levels.
11. Almaghrabi, B. K. (2012). Saudi college students'independent language learning strategies through multimedia resources: Perceptions of benefits and implications for language learning. MA Thesis, Southern Illinois University.

This study examined the out-of-class use of multimedia resources for language learning purposes. A sample of 42 Saudi college students responded to a survey of 25 items about frequency and purposes of use of different online and offline multimedia resources. The study was guided by specific research questions as follows: 1) how frequently do Saudi English learners use different multimedia resources in English? 2) What are the most frequent language purposes for which these resources are used? 3) How do Saudi college students perceive the overall usefulness of multimedia resources in relation to different language skills? 4) Is there a difference between male and female Saudi English learners in their frequency and purposes of using online and offline multimedia resources to learn English as a foreign language? Results indicated that participants of both gender groups are habitually using one or another online or offline multimedia resource for their independent language learning. In addition, several gender differences were found in terms of frequency and purposes of using specific online and offline multimedia resources as well as in overall perceived benefits for particular language skills. Particularly, female participants seemed to utilize multimedia resources with the purpose of improving their pronunciation, speaking and communication skills, vocabulary knowledge, reading and writing skills with more persistency than their male counterparts. Results of the study offered insights into types of online and offline resources that can be effectively incorporated into the language curriculum.

12. Almandil, S. I. (1999). An investigation into strategy use and background variables in learning English: The case of tertiary level Students in Saudi Arabia. PhD Thesis, University of London.

This study evaluated the interrelationship of three variables related to 40 students in King Faisal University as they engaged in the complex process of acquiring English as a foreign language during the academic year 1993-1994. The variables are the students' learning strategies, their individual preferences, and their proficiency level. Data were collected via recorded interviews with the subjects, questionnaires, and their academic achievements in four different types of language tests. In general, all the variables were affected by the current level of English language teaching in Saudi Arabia with several points of weaknesses. Questionnaire results provided evidence of correlation between the use of learning strategies, the level of proficiency and the individual variables such as motivation, age, attendance of private schools versus government schools, extracurricular exposure to English, etc. Interviews questions focused mainly on students' language experiences, background knowledge, interest in learning English, and their linguistic abilities while they describe their life style and language learning opportunities they are exposed to outside class. The interviews indicated the predominant use of traditional methods in teaching L2 especially those focusing on translating texts and teaching 
grammar where the teacher is a performer, lecturer, and knowledge transmitter. Students' academic achievements were found to be affected by their strategy selectivity, performance, and careful choice of strategy use as an indicator of effective learning where students learn well provided they show more engagement, focused attention and active participation.

13. Almutairi, N. H. (2007). The influence of educational and sociocultural factors on the learning styles and strategies of female students in Saudi Arabia. PhD Thesis, University of Leicester.

The learning styles and strategies of female university students in Saudi Arabia were investigated in relation to their educational and sociocultural backgrounds. The participants were 209 first-year female EFL students at King Faisal University in Saudi Arabia. The study used a two-stage, sequential mixed methodology incorporating both quantitative and qualitative data. Three questionnaires were administered to obtain information on the participants' learning styles, learning strategies, and general background characteristics. Qualitative data were gathered from focus groups and observations to explore further the findings of the quantitative data. The results of both the quantitative and qualitative data suggest that the educational and sociocultural features of the learners are likely to determine the range and variety of their learning styles and strategies. The students' reported approaches to learning reflected their culturally based view of knowledge, societal expectations of schooling, and the learning system which they developed during previous years of education. In general, the students focused on using learning approaches that were appropriate for dealing with the specific requirements of their learning environment, particularly, to improve their formal learning of English and prepare them for examinations. Other styles and strategies that aim at developing analytical and more communicative competences were under-developed among these students mainly because the learning environment did not encourage their use.

14. Alnufaie, M. R. (2014). Writing strategies of Saudi Arabian ESP learners: Competence, apprehension and the role of strategy instruction. $\mathrm{PhD}$ thesis, University of Dublin.

This study involved 121 second-year undergraduate Saudi EFL students, who were studying English for specific purposes at Jubail Industrial College, to investigate their writing strategies in relation to competence in L2 writing and writing apprehension. Multi-methods of data collection were implemented including a strategy questionnaire, a writing apprehension scale, and an argumentative writing task in addition to semi-structured interviews. Findings indicated that the participants preferred to utilize' equally mixed writing strategies that are not oriented toward a particular type of instructional principles which could be considered a sign of flexibility in changing words, simplifying ideas, and thinking about the reader and purpose of writing. In addition, the majority of the participants $(57.9 \%)$ were average in their stress and apprehension towards writing strategies and (31.4\%) were highly apprehensive while only $10 \%$ did not report apprehensive feelings towards writing. 68 participants took the writing competence test and findings revealed that
$41.2 \%$ of them were low competence writers; $38.2 \%$ were average competence writers while only $20.6 \%$ were high competence writers. The correlational analysis revealed a significantly positive correlations between the types of writing strategies and both apprehension levels and competence levels. Students who tended to use more process-oriented writing strategies were low competent and high apprehensive strategy users while students who tended to use a mixture of both process-oriented and product-oriented writing strategies were the high competent writers and the low apprehensive strategy users. The eight interviewed participants reported that they tended to write only one draft and hand in their papers after checking the neatness and the layout and that the most stressful things in writing were perfectionism; lack of grammar, spelling and vocabulary skill; lack of ideas; and meeting teacher's expectations.

15. Al-Nujaidi, A. (2003). The relationship between vocabaulry size, reading strategies, and reading comprehension of EFL learners in Saudi Arabia. PhD dissertation, Oklahoma State University.

This study reported favourably on the effect of large vocabulary size and higher reading proficiency on the frequency of using reading strategies and examined how certain learner variables that may impact this relationship such as gender and the amount of extensive reading, beliefs about the role of vocabulary in language learning, and self-rated language proficiency and vocabulary knowledge. Descriptive and inferential statistics were used to describe the performance of 226 (117 females and 109 males) first-year university students on a vocabulary size test (to assess the students' knowledge of English vocabulary at three different word frequency levels) and a reading comprehension test (to assess the learners' reading comprehension ability) as well as a reading strategies survey (to examine the students' awareness of common reading strategies and their perceived frequency of use). The participants reported significantly more frequent use of problem-solving strategies and reading strategies with high and moderate frequencies. However, extensive reading was an unpopular activity for most participants who had a low reading ability and an estimated small vocabulary size (500-700 word families). Female participants performed significantly better on the two tests and their reports of reading strategies use. Participants with larger vocabulary size and higher reading proficiency had a statistically significant relationship with using reading strategies more frequently than lower proficiency students. In addition, a significantly positive correlation was found between the participants' vocabulary size at the 2000 word level and their performance on the reading comprehension test.

16. Al-Otaibi, G. (2004). Language learning strategy use among Saudi ESL students and its relationship to language proficiency level, gender and motivation. $\mathrm{PhD}$ dissertation, Indiana University of Pennsylvania.

This study aimed at investigating the language learning strategies of Saudi EFL students and the relationship between strategy use and certain factors such as language proficiency level, gender and motivation. The study had the following research questions: 1) What kind of language learning strategies do Saudi students learning EFL at the 
IPA self-report, and how often do they use those strategies? 2) How does the students' language proficiency level affect their language learning strategies? 3) Are male and female students different or similar in their language learning strategies? 4) What is the relationship between language learning strategy use and motivation? 5) What additional insights can be gained from students' own statements about their strategy use? Three instruments were used: A) the Strategy Inventory for Language Learning (SILL) was administered to 237 participants (59\% males and $41 \%$ females) from the English Language Center (ELC) at the Institute of Public Administration (IPA) in Saudi Arabia. B) Email interviews with 8 participants to learn more about their strategy use; and C) Two MSN Messenger group interviews with 5 male and 6 female participants to further investigate their perspectives on learning English. Questionnaire findings indicated that language learning strategies were used moderately with significant differences based on language proficiency level, but no significant differences were observed between male and female participants in all strategy categories while motivation correlated significantly with all strategy categories. Findings from the e-mail interviews showed that proficient and highly motivated participants used a greater number of effective strategies more frequently. Female participants utilized a more active approach to language learning, and were more inclined to communicate with English speakers. Group interviews also showed greater female strategy use, especially out-of-class strategies.

17. Alsamadani, H. (2009). The relationship between Saudi EFL college-level students' use of reading strategies and their EFL reading comprehension. $\mathrm{PhD}$ dissertation, Ohio University.

This study explored the effect of using reading strategies on students' reading comprehension. Quantitative and qualitative methods were employed to obtain information from 140 students in four higher education institutions. Results of quantitative data, obtained via the Self-Regulating Capacity in Vocabulary Learning Scale, indicated that the participants showed significantly more perceived use of planning strategies than attending strategies and evaluating strategies. They also perceived the environment as the most important factor affecting their reading comprehension. Qualitative date were collected from two reading comprehension tests each of which is followed by seven multiple-choice reading comprehension questions. The two reading comprehension passages were part of a TOEFL test. Levels of students' reading comprehension varied with 31 students classified with low comprehension, 77 with medium comprehension, and 32 with high comprehension. In addition, interviews with 10 volunteering participants were administered to investigate the students' perception on how reading comprehension contribute to understanding their use of reading strategies and awareness of the different types of reading strategies, how often they use these strategies, and what other factors they perceive as having great impact on their comprehension. Half of the participants reported using all three types of strategies (planning, attending, and evaluating) which suggests a good level of awareness of the importance of these strategies in facilitating their comprehension. The other half mentioned dif- ferent combinations of strategies as well as other factors as affecting their comprehension more than reading strategies. Significant gender differences were found favoring female students in overall strategy use, comprehension level, and the use of evaluating strategies.

18. Al-Semari, O. (1993). Saudi Students' Revising Strategies in Arabic and English Essays. PhD thesis, Michigan State University.

This study examined the revising performance of eight advanced Saudi students when writing two argumentative essays in Arabic and English. The subjects wrote and revised each essay in a sixty-minute session separately. Data were collected from first and final drafts' quality ratings as well as revisions analysis according to type, purpose, and phase, based on the video tapes of the writing sessions and thinkaloud protocols. This study might be the first of its kind to address issues of revising strategies in L1 and L2 and use qualitative methods to examine how Saudi students revise in Arabic and English and consider whether revisions would improve their Arabic and English texts or not. Overall, advanced ESL learners in this study used approximately the same pattern of revising strategies in Ll and L2 writing tasks. The subjects made the same revision types and revised for the same purposes which significantly improved the quality of writing in both essays. The overwhelming majority of changes were surface changes because the subjects made substantially more microstructure reorganization (expansion changes) than meaning-preserving reorganization (deletion changes). The study also found a number of noticeable differences between the students' Arabic and English revising techniques. The subjects made formal changes in English much more frequently than in Arabic, reorganization and deletion changes in Arabic more frequently than in English, but much more numerous grammatical and mechanical changes in English than in Arabic.

19. Alwahibee, K. M. (2000). The relationship between language learning strategies and the English language oral proficiency of Saudi university level ESL students. PhD dissertation, University of Kansas.

Oral proficiency of 105 Saudi students studying in the United States were investigated in relation to the effect of demographic factors such as affective, age, gender, academic major, length of stay in the United States, personality type (perceiving themselves as above-average, average or below-average English language proficiency), TOEFL scores, language learning experience, beliefs regarding language, and attitudes toward the American people. The study used the strategy inventory of language learning (STLL) to find out what kinds of LLS Saudi students use when learning English as a second language. Findings of the questionnaire revealed that this group of Saudi students were not very successful language learners. They scored an average of 3.1 which characterizes them as middle users of LLSs according to Oxford's (1989) scale. In particular, they used LLS in the following order: compensation, cognitive, metacognitive, social, memory and affective strategies. Successful learners, according to Oxford's (1989) scale of average use of LLS, used the following order: metacognitive strategies, cognitive strategies, compensation strategies, social strategies, 
memory strategies, and, finally, affective strategies. On the other hand, unsuccessful learners used the following order: compensation strategies, cognitive strategies, metacognitive strategies, memory strategies, social strategies and finally affective strategies. Demographic factors mentioned above were found not to have a significant relationship with LLS used by Saudi learners studying English in the US for different purposes. Qualitative data collected through interviews revealed that the current teaching method results, teachers, and educational goals proposed by policy makers do not encourage the teaching of LLS, which, in turn, would develop oral communication skills.

20. Alyami, S. (2011). Vocabulary learning strategies of Saudi EFL majors of different gender, year and proficiency: use and reasons for use. $\mathrm{PhD}$ thesis, University of Essex.

The aim of this study was to investigate Saudi EFL majors' use of vocabulary learning strategies across genders, years of study $(1+4)$ and varying degrees of vocabulary proficiency, inside and outside the classroom. Multi-modal methods were used to collect data including a questionnaire, structured interviews and vocabulary levels test. Findings revealed that males reported only using paper English-English dictionary significantly more often than females. Females reported using VLS more than males in guessing unknown vocabulary by continuing reading till the meaning of the unknown word could be unlocked, and associating the new word with their personal experience. However, there were some strategies which were used similarly by both genders such as guessing the meaning of an unknown word from its structure, asking for the word's Arabic meaning, use of on-line dictionary and organizing new words randomly. Vocabulary proficiency was found to correlate positively with strategies which require deep processing such as guessing and monolingual dictionary use. Reasons for use or non-use of VLS were found to be related in various ways to learner characteristics, the word, or the perceived nature of the strategy. In relation to the year of study factor, skipping the new word without finding out its meaning and looking up the word's grammatical category, among other things were used significantly more often by fourth-year students than firstyear students.

21. Haywood, A. L. (2005). The Relationship between Student Learning Styles and L2 Acquisition in Two International High Schools' English Language Classrooms in Jeddah, Saudi Arabia. PhD dissertation, University of Mississippi.

The author used the Learning Styles Assessment to determine students' learning styles and IDEA Proficiency test to determine their L2 acquisition, reading, and writing proficiency in two International girls high schools' English language classes in Jeddah. The experiment methodology involved three hypotheses related to the relationships between second language reading and writing scores, differences between the two schools scores, and the relationships between learning style and second language acquisition. The study results showed a strong relationship between reading and writing in L2 acquisition while there were significant differences between the schools. In addition, there were some important relationships between learning style and reading and writing scores overall.

\section{REFERENCES}

Ahmed, O. N. (2012). The effect of different learning styles on developing writing skills of EFL Saudi learners. British Journal of Arts and Social Sciences, 5(2), 220-233.

Al Maghraby, M. A. \& Alshami, A. M. (2013). Learning style and teaching method preferences of Saudi students of physical therapy. J Family Community Med, 20(3), 192-197.

Al Nooh, A. (2013). The Effectiveness of Reading Techniques Used in a Saudi Arabian Secondary School Classroom as Perceived by Students and Teachers: A Study of Methods Used in Teaching English and their Effectiveness. Arab World English Journal, 4(3), 331- 345

Al Tale', M. A. (2016). Utilizing Learning Styles in EFL Teaching. International Journal of Language and Linguistics, 3(6), 81- 86.

Al-Abbasi, J. A. A. (2007). Beliefs and vocabulary learning strategies in Saudi Arabia. PhD dissertation, University of Nottingham.

Al-Asmary A. A. (2007). The Effect of Learning Strategies on Vocabulary Learning by King Saud University Students Majoring in English. MA Thesis, King Saud University.

Albousaif, M. A. (2012). Factors determining Saudi learners' difficulties in attaining EFL vocabulary. $\mathrm{PhD}$ thesis, University of Newcastle.

Al-Braik, M. S. (1986). Investigation of the successful attributes of English as a second language of Saudi Arabian Students studying in the United States of America. $\mathrm{PhD}$ dissertation, Pennsylvania State University.

Al-Fuhaid, M. (2004) Vocabulary learning strategies: an empirical study of their use and evaluation by Saudi EFL learners majoring in English. $\mathrm{PhD}$ thesis, Durham University.

Alhaisoni, E. (2012). Language Learning Strategy Use of Saudi EFL Students in an Intensive English Learning Context. Asian Social Science, 8(13), 115-127.

Alharthi, T. (2011). The Impact of Writing Strategies on the Written Product of EFL Saudi Male Students at King Abdul-Aziz University. PhD thesis, University of Newcastle.

Alhaysony, M. (2012). Vocabulary discovery strategy used by Saudi EFL students in an intensive English language learning context. International Journal of Linguistics, 4(2), 518- 535.

Alhaysony, M. H. (2008). Saudi-female English major students' writing strategies in L1 (ARABIC) AND L2 (English). $\mathrm{PhD}$ thesis, University of Essex

Al-Hebaishi, S. M. (2012). Investigating the relationships between learning styles, strategies and the academic performance of Saudi English majors. International Interdisciplinary Journal of Education, 1(8), 510-520.

Aljuaid, H. (2015). Language Learning Strategies Used by a Group of Saudi Arabian EFL Learners. PhD thesis, Griffith University.

Alkahtani, M. (2011). Learning styles of EFL Saudi college-level students in online and traditional educational 
environments. $\mathrm{PhD}$ dissertation, Indiana University of Pennsylvania.

Alkahtani, S. S. (2016). Language learning strategies among Saudi EFL college students and their relationship to students' perceptual learning style, gender, academic major and proficiency level. $\mathrm{PhD}$ dissertation, University of Tennessee.

Alkubaidi, M. A. (2014). The relationship between Saudi English major university students' writing performance and their learning style and strategy use. English Language Teaching, 7(4), 83-95.

Almaghrabi, B. K. (2012). Saudi college students' independent language learning strategies through multimedia resources: Perceptions of benefits and implications for language learning. MA Thesis, Southern Illinois University.

Almandil, S. I. (1999). An investigation into strategy use and background variables in learning English: The case of tertiary level Students in Saudi Arabia. PhD Thesis, University of London.

Almigbal, T. H. (2015). Relationship between the learning style preferences of medical students and academic achievement. Saudi Medical Journal, 36(3), 349-355.

Almutairi, N. H. (2007). The influence of educational and sociocultural factors on the learning styles and strategies of female students in Saudi Arabia. PhD Thesis, University of Leicester.

Alnufaie, M. R. (2014). Writing strategies of Saudi Arabian ESP learners: Competence, apprehension and the role of strategy instruction. PhD thesis, University of Dublin.

Al-Nujaidi, A. (2003). The relationship between vocabaulry size, reading strategies, and reading comprehension of EFL learners in Saudi Arabia. PhD dissertation, Oklahoma State University.

Al-Otaibi, G. (2004). Language learning strategy use among Saudi ESL students and its relationship to language proficiency level, gender and motivation. $\mathrm{PhD}$ dissertation, Indiana University of Pennsylvania.

Alqarni, I. R. (2018). Saudi English Major Freshmen Students' Vocabulary Learning Strategies: An Exploratory Study. International Journal of Applied Linguistics \& English Literature, 7(1), 141-145.

Al-Refay, N. \& Koura, A. (2010). Language Learning Strategies Used by Saudi secondary School Students and their Relationship to Achievement in ESL. $30^{\text {th }}$ CDELT
National Symposium on English Language Teaching. $26^{\text {th }}-27^{\text {th }}$ October. AinShams University. Cairo

Alsamadani, H. (2009). The relationship between Saudi EFL college-level students' use of reading strategies and their EFL reading comprehension. $\mathrm{PhD}$ dissertation, Ohio University.

Al-Saud, L. M. 2013 Learning Style Preferences of FirstYear Dental Students at King Saud University in Riyadh, Saudi Arabia: Influence of Gender and GPA. Journal of Dental Education, 77(10), 1371-1378

Al-Seghayer, K. (2014). The impact of gender and reading proficiency level on online reading strategies employed by EFL learners. Journal of Educational Sciences of King Saud University, 6 (2), 493-509.

Al-Semari, O. (1993). Saudi Students' Revising Strategies in Arabic and English Essays. PhD thesis, Michigan State University.

Alwahibee, K. M. (2000). The relationship between language learning strategies and the English language oral proficiency of Saudi university level ESL students. $\mathrm{PhD}$ dissertation, University of Kansas.

Alyami, S. (2011). Vocabulary learning strategies of Saudi EFL majors of different gender, year and proficiency: use and reasons for use. $\mathrm{PhD}$ thesis, University of Essex.

Arif A. M. H. Al-Ahdal \& A. A. H. Al-Ma'amari. (2015). Learning Strategies of the Arab EFL Learners: Finding Correlation with Outcomes. Advances in Language and Literary Studies, 6(5), 230-241.

Choudhary Z. J., Al-thubaiti, T. S., \& Uthman, A. (2013). Effects of English language proficiency on the choice of language learning strategies by Saudi English-major undergraduates. English Language Teaching, 6(1), 35-47.

Haywood, A. L. (2005). The Relationship between Student Learning Styles and L2 Acquisition in Two International High Schools' English Language Classrooms in Jeddah, Saudi Arabia. PhD dissertation, University of Mississippi.

McMullen, M. G. (2009). Using Language Learning Strategies to Improve the Writing Skills of Saudi EFL Students: Will it Really Work? System, 37(3). 418-433.

Nuzhat, A., Salem, R., Quadri, M., \& Al-Hamdan, N. (2011). Learning style preferences of medical students: a single-institute experience from Saudi Arabia. International Journal of Medical Education; Nottingham, 2. 70-73. 